\title{
PENGARUH GRIT DAN GENDER DALAM PENGAMBILAN KEPUTUSAN KARIR MAHASISWA
}

\author{
Sovi Septania ${ }^{1}$, Khairani ${ }^{2}$ \\ sovi.septania@umla.ac.id \\ Universitas Muhammadiyah Lampung
}

\begin{abstract}
Abstrak: Rapid development of technology and challenges in upcoming industrial revolution 4.0 require students to equip themselves with relevant competencies. The success of students as prospective workers will depend on this. Initial stage for students is to have clarity on the direction of career preparation. Adequate career preparation, including the accuracy of career decision making is synchronized between their potential versus what is desired (Sharf, 2002). Internal factorof students' success in choosing a future career is by having strong characters. Character with perseverance and great desire to achieve long-term goals in a long time is known as grit ((Duckworth, Peterson, Matthews \& Kelly, 2007). This study aims to identify the influence of grit and gender on career decision making among Psychology faculty's students in UniversitasMuhammadiyah Lampung. The research involved 83 students from 4 classes and using quantitative research method using a scale as a data collection tool. Results of empirical research prove that grit and gender are proven to significantly influence students' career decision making. Grit correlate to career decision making with pearson-correlation score $0.519(\mathrm{p}<0.001)$ and gender correlate to career decision making with pearson-correlation score 0.277 ( $\mathrm{p}<0.005)$. Simultaneously, grit and gender make $28 \%(\mathrm{p}<0.000)$ effective contribution to student's career decision making. Further research is expected to be able to examine the interventions that can be done to improve the ability of taking career decisions for students.
\end{abstract}

Keywords: Grit, Career Decision Making, Students

\section{A. PENDAHULUAN}

Dunia kerja adalah tujuan pertama dan utama ketika mahasiswa sudah mendapatkan gelar sarjana. Hal ini menuntut mahasiswa agar membekali diri dengan kompetensi yang akan memudahkan untuk mendapatkan pekerjaan impian. Kompetisi antar pencari kerja yang semakin ketat dan perkembangan revolusi indutri 4.0 secara langsung akan berdampak terhadap keberdayasaingan mahasiswa sebagai calon tenaga kerja produktif. Tantangan terbesar mahasiswa saat ini adalah

Secara nasional, data Badan Pusat Statistik $^{1}$ menyatakan bahwa jumlah angkatan kerja pada Februari 2019

\footnotetext{
${ }^{1}$ Badan Pusat Statistik. (2019). Tingkat Pengangguran Terbuka (TPT) sebesar 5.01 persen. BPS (online), (diakses tanggal $20 \mathrm{Mei}$ 2019 ,

https://www.bps.go.id/pressrelease/2019/05/06/15 64/februari-2019--tingkat-pengangguran-terbuka-tpt--sebesar-5-01-persen.html)
} 
sebanyak 136,18 juta orang, naik 2.24 juta orang dibandingkan Februari 2018. Tingkat partisipasi angkatan kerja (TPAK) juga meningkat sebesar 0.12 persen poin dan tingkat pengangguran terbuka (TPT) pada bulan Februari 2019 sebesar 5.01 persen. Tingkat pengangguran ini, walaupun dinyatakan turun dibandingkan tahun sebelumnya, tetap menunjukan adanya tingkat pengangguran yang cukup tinggi. Bahkan di tahun 2015, Indonesia tercatat sebagai negara dengan tingkat pengangguran tertinggi di Asia Tenggara. Merujuk pada kondisi ini, maka mahasiswa yang saat ini masih menempuh jenjang pendidikan tinggi, harus siap dengan persaingan yang semakin meningkat ketika mereka mendapatkan gelar sarjana.

Saat ini, indikator keberhasilan mahasiswa di Indonesia terukur dengan menggunakan standar Indeks Prestasi Kumulatif (IPK). IPK diperoleh berdasarkan nilai kumulatif seluruh matakuliah yang telah diperoleh selama perkuliahan dengan nilai IPK tertinggi berada pada skor 4.0. Seiring dengan perkembangan kebutuhan akan tenaga kerja yang terampil, maka IPK ini tidak lagi cukup membekali mahasiswa untuk mampu bersaing dalam kompetisi dunia kerja. Awaliyah ${ }^{2}$ menyatakan bahwa penyesuaian konsep yang sejalan dengan perkembangan zaman sangat penting agar dapat melengkapi diri dengan berbagai keterampilan baik teknis (hardskill) dan softskill, pengetahuan dan kemampuan yang akan mendukung keberlanjutan karir seperti kebiasan kerja yang baik, pandai

\footnotetext{
${ }^{2}$ Gumanti Awaliyah, (2018). Mahasiswa Tidak Hanya Butuh Gelar Untuk Bekerja. Republika (Online),(diakses tanggal 20 Mei 2019,https://www.republika.co.id/berita/pendidika n/dunia-kampus/18/09/25/pfly0k366-mahasiswatidak-hanya-butuh-gelar-untuk-bekerja).
}

berkomunikasi, memiliki jiwa kepemimpinan yang baik dan memiliki empati yang baik terhadap rekan kerja.

Revolusi industri 4.0 merupakan salah satu tantangan terbesar lain bagi calon tenaga kerja. Drath \& Horch $^{3}$ menyatakan bahwa revolusi industri 4.0 belum benar-benar terjadi dan masih dalam bentuk gagasan. Hal ini merupakan peluang emas bagi para pesaing industri kerja yang mampu mempersiapkan diri terhadap perubahan yang diprediksi akan terjadi. Potensi manfaat revolusi industry 4.0 adalah adanya perbaikan kecepatan fleksibilitas produksi, peningkatan layanan kepada pelanggan dan peningkatan pendapatan. Terwujudnya potensi manfaat itu akan memberi dampak positif terhadap perekonomian suatu negara ${ }^{4}$.

Terdapat 10 aspek dalam industri 4.0 yaitu standarisasi, pemodelan, jaringan komunikasi, safety security, SDM, hukum, efisiensi SDM, teknologi CPS, smart factory, bisnis, desain kerja, services, manajemen organisasi dan rekayasaya produksi end to end ${ }^{5}$. Hal terpenting dan sebagai faktor penentu keberhasilan dalam menghadapi industri 4.0 adalah kesiapan sumber daya manusia baik dalam hal peningkatan kompetensi juga mempersiapkan calon-calon tenaga kerja baru dengan kompetensi yang telah disesuaikan dengan kebutuhan. Salah satu

${ }^{3}$ R. Drath, \& Horch, A. (2014). Industri 4.0: Hit or hype? [industry forum]. IEEE industrial electronics magazine, 8(2), pp. 56-58.

${ }^{4}$ Hoedi Prasetyo, \& Wahyudi, Sutopo. (2017). Industri 4.0: Telaah Klasifikasi Aspek dan Arah Perkembangan Riset. Jurnal Teknik Industri UNDIP, Vol. 13, No. 1, Januari 2018.

${ }^{5}$ R. Neugebauer, Hippmann, S., Leis, M., \& Landherr, M. (2016). Industrie 4.0-From the Perspective of Applied Research. Procedia CIRP, Vol. 57, pp. 2-7. 
manfaat dari industri 4.0 pun menyasar pada potensi SDM yang tidak terbatas, sehingga akan terjadi perbaikan produktivitas dan peningkatan tenaga kerja yang terampil ${ }^{6}$. Dampak dari industri 4.0 ini akan terjadi secara menyeluruh, tidak terkecuali lembaga pendidikan tinggi atau universitas yang harus segera menyesuaikan kurikulum yang ada agar kompetensi yang dimiliki oleh mahasiswa sebagai calon tenaga kerja sesuai dengan kebutuhan di masa depan.

Melihat kebutuhan ini maka dibutuhkan kesiapan yang matang dan strategis. Persiapan yang dimaksud dimulai dari masing-masing calon tenaga kerja agar mampu menjadikan setiap potensi dalam diri dan latar belakang pendidikan, menjadikannya sebagai salah satu calon tenaga kerja yang mampu bersaing di kompetisi industri 4.0. Hal ini erat terkait tentang perencanaan dan pengambilan keputusan karir.

Universitas Muhammadiyah Lampung (UML) sebagai salah satu universitas swasta di Lampung memiliki tantangan yang sama bahkan lebih tinggi bila dibandingkan dengan lulusan universitas negeri. UML saat ini memiliki Fakultas Psikologi yang menjadi satusatunya fakultas psikologi di Lampung yang telah terakreditasi. Hal ini menjadi keunggulan sekalian tantangan bagi para mahasiswanya. Peluang kerja psikologi sangat banyak, seperti bidang kerja personalia di perusahaan, konselor, peneliti, terapis anak berkebutuhan khusus, trainer hingga asisten psikolog.

${ }^{6}$ M. Rüßmann, Lorenz, M., Gerbert, P., Waldner, M., Justus, J., Engel, P. \& Harnisch, M. (2015). Industry 4.0: The future of productivity and growth in manufacturing industries. Boston Consulting Group, p.14.
Banyaknya peluang ini, bila tidak dimulai dengan perencanaan karir yang baik, maka mahasiswa akan salah dalam menentukan kompetensi khusus apa yang akan mendorong mahasiswa mengambil keputusan karir yang terbaik.

$$
\text { Karir menurut Arnold }
$$
didefinisikan sebagai urutan posisi yang terkait pekerjaan, peran, kegiatan dan pengalaman yang dihadapi seseorang.Untuk itu, persiapan karir yang memadai, diantaranya ketepatan pengambilan keputusan karir agar apa yang dimiliki (potensi) sesuai dengan yang diinginkan. Keterampilan dalam mengambil keputusan karir sangat dibutuhkan agar ketepatan dalam memutuskan karir yang akan dipilih dan dijalani dapat tercapai.

Proses pengambilan keputusan karir ini tentu bukan hal yang mudah. Membutuhkan proses panjang, membutuhkan dukungan internal maupun eksternal agar keputusan yang diambil berhasil mencapai hasil yang diharapkan. Salah satu dukungan internal yang dibutuhkan oleh mahasiswa agar mencapai kesuksesan adalah karakter positif yang mendorong mahasiswa untuk selalu konsisten dan tekun dalam berusaha. Karakter ini dikenal dengan nama grit. Grit didefinisikan secara umum didefinisikan sebagai ketekunan dan keinginan besar untuk mencapai tujuan jangka panjang dalam waktu yang lama ${ }^{7}$. Grit akan memunculkan daya kerja yang kuat terhadap tantangan yang dihadapi,

${ }^{7}$ A.L. Duckworth, Peterson, C., Matthews, M.D., \& Kelly, D.R. (2007). Grit: perseverance processes and passion for long-term goals. Journal of Personality and Social Psychology, Vol. 9, No. 6 , page 1087-1101. DOI. 10.1037/00223514.92.6.1087. 
mempertahankan usaha dan ketertarikan dari tahun ke tahun walaupun ada kegagalan, kemalangan dan hambatan dalam prosesnya. Dalam bukunya yang berjudul Grit: Kekuatan Passion dan Kegigihan yang ditulis oleh Duckworth ${ }^{8}$, dinyatakan bahwa hal terpenting untuk sukses dan bahagia bukanlah bakat, tetapi keteguhan hati dan kegigihan, inilah yang disebut sebagai grit.

Karakter grit ini berdampak besar dalam mencapai tujuan dan kesuksesan. Duckworth (2018) menyimpulkan bahwa semakin gritseseorang, semakin besar kemungkinan orang tersebut untuk menikmati kehidupan emosional yang sehat serta berdampak pada kesejahteraan psikologis. Penelitian yang dilakukan oleh Eskreis-Winkler, Shulman, Beal dan Duckworth (2014) membuktikan secara empirik bahwa grit mampu memprediksi turnover bahkan melebihi prediktor lainnya. Penelitian yang dilakukan pada empat konteks yang berbeda memberikan hasil yang positif, seperti prajurit yang memiliki level grit yang lebih tinggi akan lebih mampu menyelesaikan pelatihan army special operations forces (ARSOF), karyawan penjualan dengan level grit yang lebih tinggi akan lebih mampu bertahan dalam pekerjaan saat ini, pelajar dengan level grit yang lebih tinggi akan lebih mampu lulus sekolah dengan lebih baik dan laki-laki dengan level grit yang lebih tinggi akan lebih mampu bertahan dalam sebuah pernikahan.

Berdasarkan penjelasan diatas dan masih kurangnya literasi yang mengaitkan karakter positif grit dengan pengambilan keputusan karir mahasiswa, maka peneliti akan mengidentifikasi pengaruh grit

\footnotetext{
${ }^{8}$ Angela Duckworth, (2018). Grit: Kekuatan Passion dan Keteguhan. Jakarta: PT. Gramedia.
}

terhadap pengambilan keputusan karir mahasiswa Fakultas Psikologi Universitas Muhammadiyah Lampung.

\section{B. METODOLOGI PENELITIAN}

Penelitian ini akan menggunakan metode penelitian kuantitatif. Metode kuantitatif akan menggunakan penelitian survei yang memaparkan secara kuantitatif kecenderungan, sikap, atau opini dari suatu populasi tertentu dengan meneliti satu sampel dari populasi tersebut ${ }^{9}$. Dalam penelitian survei ini akan digunakan skala sebagai alat pengumpul data yang merupakan suatu alat ukur atribut non-kognitif ${ }^{10}$.Skala likert digunakan untuk mengukur sikap, pendapat dan persepsi seseorang atau sekelompok orang tentang fenomena sosial. Variabel penelitian yang akan diukur, akan dijabarkan ke dalam indikator perilaku dan digunakan sebagai dasar penyusunan aiteminstrumen yang berupa pernyataan atau pertanyaan.

Alat Ukur yang digunakan untuk mengukur grit karyawan adalah skala grit yang disusun oleh Duckworth, Peterson, Matthews dan Kelly ${ }^{11}$. Skala ini menggunakan dua aspek utama yaitu konsisten terhadap ketertarikan dan ketekunan dalam berusaha. Alat ukur pengambilan keputusan karir disusun dengan menggunakan teori Betz (2004) dengan lima aspek yaitu penilaian diri (self-appraisal), informasi kerja (occupational information), seleksi tujuan (goal selection), perencanaan (planning)

${ }^{9}$ H.D. Darmadi, (2014). Metode Penelitian Pendidikan dan Sosial. Bandung: Alfabeta

${ }^{10}$ Syaifuddin Azwar, (2013). Penyusunan Skala Psikologi: Edisi 2. Yogyakarta: Pustaka Pelajar.

${ }^{11}$ A.L. Duckworth, Peterson, C., Matthews, M.D., \& Kelly, D.R. (2007). Op.Cit. 


\section{sis}

dan penyelesaian masalah (problem solving).

Penelitian ini akan melibatkan 83 orang mahasiswa Fakultas Psikologi Universitas Muhammadiyah Lampung yang terdiri dari 4 angkatan yaitu angkatan 2015-2018. Teknik sampling dalam penelitian ini adalah teknik purposive sampling dengan kriteria subjek adalah mahasiswa aktif fakultas psikologi Univeritas Muhammadiyah Lampung dan sudah melewati minimal 2 semester saat penelitian dilakukan.

Penelitian ini akan menggunakan metode penelitian kuantitatif. Metode kuantitatif akan menggunakan penelitian survei yang memaparkan secara kuantitatif kecenderungan, sikap, atau opini dari suatu populasi tertentu dengan meneliti satu sampel dari populasi tersebut ${ }^{12}$. Dalam penelitian survei ini akan digunakan skala sebagai alat pengumpul data yang merupakan suatu alat ukur atribut non-kognitif ${ }^{13}$. Skala likert digunakan untuk mengukur sikap, pendapat dan persepsi seseorang atau sekelompok orang tentang fenomena sosial. Variabel penelitian yang akan diukur, akan dijabarkan ke dalam indikator perilaku dan digunakan sebagai dasar penyusunan aiteminstrumen yang berupa pernyataan atau pertanyaan.

Alat Ukur yang digunakan untuk mengukur grit karyawan adalah skala grit yang disusun oleh Duckworth, Peterson, Matthews dan Kelly. Skala ini menggunakan dua aspek utama yaitu konsisten terhadap ketertarikan dan ketekunan dalam berusaha. Alat ukur pengambilan keputusan karir disusun dengan menggunakan teori Betz (2004)

\footnotetext{
${ }^{12}$ H.D. Darmadi, Op.Cit.

${ }^{13}$ Syaifuddin Azwar, Op.Cit.
}

dengan lima aspek yaitu penilaian diri (self-appraisal), informasi kerja (occupational information), seleksi tujuan (goal selection), perencanaan (planning) dan penyelesaian masalah (problem solving).

Penelitian ini akan melibatkan 83 orang mahasiswa Fakultas Psikologi Universitas Muhammadiyah Lampung yang terdiri dari 4 angkatan yaitu angkatan 2015-2018. Teknik sampling dalam penelitian ini adalah teknik purposive sampling dengan kriteria subjek adalah mahasiswa aktif fakultas psikologi Univeritas Muhammadiyah Lampung dan sudah melewati minimal 2 semester saat penelitian dilakukan.

\section{HASIL PENELITIAN}

Dilakukan pengukuran mean, standard deviasi $(S D)$ dan skor minimal maksimal yang diperoleh berdasarkan data hipotetik maupun empirik. Berdasarkan data empirik, pada variabel grit diperoleh skor pengambilan keputusan karir, skor minimum 31 dan skor maksimum 62 dengan nilai rata-rata sebesar 48.63. Pada variabel pengambilan keputusan karir diperoleh skor minimum 66 dan skor maksimum 129 dengan nilai rata-rata sebesar 103.72.

Skala gritmenunjukan rentang indeks daya diskriminasi aitem bergerak antara 0,323 - 0,597 dengan nilai alpha Cronbach sebesar 0.747.Skala pengambilan keputusan karir menunjukan rentang indeks daya diskriminasi aitem bergerak antara 0.356- 0.654 dengan nilai alpha cronbach sebesar0.892. Berdasarkan hasil koefisien reliabilitas tersebut, maka kedua skala dapat dikategorisasikan sebagai skala yang baik untuk digunakan.Hasil analisis faktor menunjukan hasil Kaiser-Meyer-Olkin 
0,500 dan Bartlett's Test of Sphericity $0,000(\mathrm{P}<0,01)$.

Uji linearitas menunjukan nilai deviation from linearity sign. 0.059 ( $>>0.005)$ maka ada hubungan linear antar variabel. Nilai $F_{\text {hitungyaitu }} 1.670$ lebih besar dari $\mathrm{F}_{\text {tabel }}$ maka ada hubungan linear yang signifikan antar variabel. Hasil uji Kolmogorov-smirnov dengan hasil 0.047 dan nilai signifikansi Asymp.sig. (2tailed) sebesar $0.200(>0.05)$ maka data dinyatakan berdistribusi normal.

Tabel 1. Komposisi Demografi Subjek Penelitian ( $\mathrm{N}=83)$

\begin{tabular}{lcc}
\hline Karakteristik & Jumlah & $\%$ \\
\hline & Jenis Kelamin \\
\hline Laki-Laki & 61 & $73 \%$ \\
\hline Wanita & 22 & $27 \%$ \\
\hline \multicolumn{3}{c}{ Angkatan } \\
\hline 2015 & 9 & $11 \%$ \\
\hline 2016 & 23 & $28 \%$ \\
\hline 2017 & 25 & $30 \%$ \\
\hline 2018 & 26 & $31 \%$ \\
\hline
\end{tabular}

Untuk melihat perbedaan antar skor di masing-masing variabel dengan lebih jelas, maka dilakukan analisis berdasarkan kategorisasi yang telah ditetapkan. Hasil dari masing-masing variabel terdapat pada tabel dibawah ini:

Tabel 2. Hasil Kategorisasi Empirik Skor Grit

\begin{tabular}{cccc}
\hline \multicolumn{4}{c}{ Kategorisasi Empirik } \\
\hline Kategori & $\begin{array}{c}\text { Rentang } \\
\text { Nilai }\end{array}$ & Jumlah & $\%$ \\
\hline $\begin{array}{c}\text { Sangat } \\
\text { Rendah }\end{array}$ & $\mathrm{X} \leq 39$ & 5 & $6 \%$ \\
\hline Rendah & $39<\mathrm{X} \leq 45$ & 19 & $23 \%$ \\
\hline Sedang & $45<\mathrm{X} \leq 48$ & 15 & $18 \%$ \\
\hline Tinggi & $48<\mathrm{X} \leq 54$ & 34 & $41 \%$ \\
\hline
\end{tabular}

\begin{tabular}{llll}
\hline $\begin{array}{l}\text { Sangat } \\
\text { Tinggi }\end{array}$ & $\mathrm{X}>54$ & 11 & $12 \%$ \\
\hline
\end{tabular}

Tabel 3. Hasil Kategorisasi Empirik Skor

Pengambilan Keputusan Karir

\begin{tabular}{lccc}
\hline \multicolumn{4}{l}{ Kategorisasi Empirik } \\
\hline Kategori & $\begin{array}{l}\text { Rentang } \\
\text { Nilai }\end{array}$ & Jumlah & $\%$ \\
\hline $\begin{array}{l}\text { Sangat } \\
\text { Rendah }\end{array}$ & $\mathrm{X} \leq 83$ & 4 & $5 \%$ \\
\hline Rendah & $83<\mathrm{X} \leq 96$ & 18 & $22 \%$ \\
\hline Sedang & $96<\mathrm{X} \leq 103$ & 15 & $18 \%$ \\
\hline Tinggi & $103<\mathrm{X} \leq 123$ & 37 & $45 \%$ \\
\hline $\begin{array}{l}\text { Sangat } \\
\text { Tinggi }\end{array}$ & $\mathrm{X}>123$ & 9 & $10 \%$ \\
\hline
\end{tabular}

Berdasarkan hasil kategorisasi diatas, dapat disimpulkan bahwa subjek memiliki skor grit pada kategori sangat rendah sebesar $6 \%$, rendah sebesar $23 \%$, sedang sebesar 18\%, tinggi sebesar $41 \%$ dan sangat tinggi sebesar 12\%. Pada pengambilan keputusan karir, subjek memiliki memiliki skor pada kategori sangat rendah sebesar 5\%, rendah sebesar $22 \%$, sedang sebesar $18 \%$, tinggi sebesar $45 \%$ dan sangat tinggi sebesar $10 \%$. Masih terdapat 29\% mahasiswa dengan karakter grit dibawah rata-rata dan $27 \%$ mahasiswa memiliki kesulitan dalam mengambil keputusan.

Analisis dilakukan dengan menggunakan program SPSS melalui uji korelasi variabel independen grit dan gender terhadap pengambilan keputusan karir. Hasil pearson-correlationgrit terhadap pengambilan keputusan karir sebesar $0.519 \quad(\mathrm{p}<0.001)$ dan korelasi gender terhadap pengambilan keputusan karir sebesar $0.277 \quad(p<0.005)$. Hasil ini menunjukkan bahwa gritdan gender berkorelasi secara signifikan terhadap pengambilan keputusan karir. 
Hasilnya uji regresi menunjukkan bahwa secara signifikan gritdan gender berpengaruh terhadap pengambilan keputusan karir dengan taraf signifikansi $1 \%(\mathrm{p}<0.01)$ dan besar sumbangan grit dan gender terhadap pengambilan keputusan karir dalam determinasi $\mathrm{R}^{2}$ sebesar $28 \%$.

Berdasarkan hasil ini, maka hipotesis awal penelitian yang menyatakan bahwa gritdan gender berpengaruh secara signifikan terhadap pengambilankeputusankarir mahasiswa fakultas psikologi UML terbukti dengan besarnya sumbangan efektif sebesar $28 \%$.

\section{DISKUSI}

Subjek penelitian melibatkan 83 orang mahasiswa yang berasal dari 4 angkatan, yaitu angkatan 2015-2018. Jumlah subjek wanita sebanyak 61 orang dan laki-laki sebanyak 22 orang. Tidak meratanya jumlah subjek laki-laki dan wanita didasarkan pada fakta di lapangan bahwa peminat atau mahasiswa fakultas psikologi UML $73 \%$ merupakan mahasiswi. Hal ini bisa menjadi indikator tersendiri bahwa minat karir untuk masuk ke fakultas psikologi didominasi oleh wanita.

Dari total 83 mahasiswa, 9 orang merupakan angkatan 2015 (semester 8), 23 orang angkatan 2016 (semester 6), 25 orang angkatan 2017 (semester 4) dan 26 orang angkatan 2018 (semester 2). Jumlah angkatan atas (semester 8) tergolong sedikit karena sudah tidak memiliki mata kuliah di perkuliahan dan sedang mengerjakan tugas akhir skripsi, sehingga proses pengambilan data mahasiswa semester atas hanya sedikit. Angkatan 2016-2018 yang masih memiliki mata kuliah wajib tersebar menjadi menjadi tiga kelas perkuliahan.
Data kategorisasi empiris menunjukan bahwa subjek memiliki skor grit pada kategori sangat rendah sebesar $6 \%$, rendah sebesar $23 \%$, sedang sebesar $18 \%$, tinggi sebesar $41 \%$ dan sangat tinggi sebesar $12 \%$. Pada pengambilan keputusan karir, subjek memiliki memiliki skor pada kategori sangat rendah sebesar $5 \%$, rendah sebesar $22 \%$, sedang sebesar $18 \%$, tinggi sebesar $45 \%$ dan sangat tinggi sebesar $10 \%$. Dapat disimpulkan bahwa terdapat $29 \%$ mahasiswa dengan karakter grit dibawah rata-rata dan $27 \%$ mahasiswa memiliki kesulitan dalam mengambil keputusan.

Hasil pearson-correlationgrit terhadap pengambilan keputusan karir diperoleh hasil sebesar $0.519 \quad(\mathrm{p}<0.001)$ dan korelasi gender terhadap pengambilan keputusan karir sebesar $0.277(\mathrm{p}<0.005)$. Hasil ini menunjukkan bahwa gritdan gender berkorelasi secara signifikan terhadap pengambilan keputusan karir.Analisis uji regresi menunjukkan bahwa secara signifikan gritdan gender berpengaruh terhadap pengambilan keputusan karir dengan taraf signifikansi $1 \%(\mathrm{p}<0.01)$ dan secara bersama-sama grit dan gender memilikisumbangan efektif terhadap pengambilan keputusan karir dalam determinasi $\mathrm{R}^{2}$ sebesar $28 \%$.

Berdasarkan kajian literasi yang telah dibahas sebelumnya, grit didefinisikan secara umum didefinisikan sebagai ketekunan dan keinginan besar untuk mencapai tujuan jangka panjang dalam waktu yang lama (Duckworth, Peterson, Matthews \& Kelly, 2007). Grit akan memunculkan daya kerja yang kuat terhadap tantangan yang dihadapi, mempertahankan usaha dan ketertarikan dari tahun ke tahun walaupun ada kegagalan, kemalangan dan hambatan 
dalam prosesnya. Ketika seseorang memiliki ketekunan dan konsistensi dalam mencapai tujuannya maka proses perencanaan karir secara jangka panjang akan terpengaruh secara positif. Seseorang dengan karakter grit yang baik akan mempersiapkan karir secara memadai yang ditunjukan dengan pengambilan keputusan karir yang disesuaikan dengan potensi dan dengan harapan.

Gender secara signifikan berpengaruh terhadap pengambilan keputusan karir mahasiwa. Mean skor wanita menunjukan data lebih rendah dibandingkan mean skor laki-laki dalam mengambil keputusan karir. Mean wanita yaitu sebesar 100.84 sedangkan mean laki-laki sebesar 108.14. Hal ini menunjukan bahwa laki-laki secara empiris terbukti lebih mudah mengambil keputusan karir dibandingkan wanita berdasarkan nilai rerata skor.

\section{E. KESIMPULAN}

Hasil penelitian ini secara empiris membuktikan bahwa terdapat pengaruh yang signifikan antara grit dan gender terhadap pengambilan keputusan karir mahasiswa fakultas Psikologi Universitas Muhammadiyah Lampung. Besarnya sumbangan efektif grit dan gender terhadap pengambilan keputusan karir mahasiswa yaitu sebesar $28 \%$, sehingga $72 \%$ disebabkan oleh faktor lain.

Penelitian sebelumnya dengan tema dan konstrak teori yang sama menghubungkan kesulitan pengambilan keputusan dipengaruhi oleh pengharapan orang tua dan orientasi nilai budaya ${ }^{14}$.

${ }^{14}$ S. A. Leung, Hou, Z. J., Gati, I., \& Li, X. (2011). Effects of parental expectations and cultural-values orientation on career decisionmaking difficulties of Chinese University students. Journal of Vocational Behavior, 78(1), 11-20. http://doi.org/10.1016/j.jvb.2010.08.004.
Perbedaan status sosial yang dimoderasi oleh identitas pekerjaan berpengaruh dalam pengambilan keputusan karir ${ }^{15}$. Perbedaan sumber dukungan sosial berpengaruh dalam pengambilan keputusan karir.

Agar generalisasi penelitian ini bisa dilakukan dengan lebih komprehensif, maka dibutuhkan sampel penelitian yang lebih luas. Selain itu, dibutuhkan penelitian lanjutan untuk mengetahui secara empirik faktor-faktor lain yang berpengaruh terhadap kemampuan pengambilan keputusan karir. Intervensi untuk meningkatkan kemampuan mahasiswa dalam pengambilan keputusan karir dapat direncanakan dan diukur efektivitasnya sebagai penelitian lanjutan.

\section{DAFTAR KEPUSTAKAAN}

Awaliyah, Gumanti. (2018). Mahasiswa Tidak Hanya Butuh Gelar Untuk Bekerja. Republika (Online),(diakses tanggal 20 Mei 2019,https://www.republika.co.id/ berita/pendidikan/duniakampus/18/09/25/pfly0k366mahasiswa-tidak-hanya-butuhgelar-untuk-bekerja).

Azwar, Syaifuddin. (2013). Penyusunan Skala Psikologi: Edisi 2. Yogyakarta: Pustaka Pelajar.

Badan Pusat Statistik. (2019). Tingkat Pengangguran Terbuka (TPT) sebesar 5.01 persen. BPS (online), (diakses tanggal 20 Mei 2019, https://www.bps.go.id/pressrelease /2019/05/06/1564/februari-2019--

${ }^{15}$ X. Li, Hou, Z.-J., \& Jia, Y. (2015). The influence of social comparison on career decisionmaking: Vocational identity as a moderator and regret as a mediator. Journal of Vocational Behavior, $\quad 86, \quad 10-\quad 19$. http://doi.org/10.1016/j.jvb.2014.10. 003 


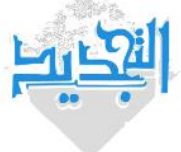

tingkat-pengangguran-terbuka--tpt-sebesar-5-01-persen.html)

Darmadi, H.D. (2014). Metode Penelitian Pendidikan dan Sosial. Bandung: Alfabeta

Drath, R., \& Horch, A. (2014). Industri 4.0: Hit or hype? [industry forum]. IEEE industrial electronics magazine, 8(2), pp. 56-58.

Duckworth, Angela. (2018). Grit: Kekuatan Passion dan Keteguhan. Jakarta: PT. Gramedia

Duckworth, A.L., Peterson, C., Matthews, M.D., \& Kelly, D.R. (2007). Grit: perseverance processes and passion for long-term goals. Journal of Personality and Social Psychology, Vol. 9, No. 6, page 1087-1101. DOI. 10.1037/00223514.92.6.1087.

Eskreis-Winkler, L., Shulman, E.P., Beal, S.A., \& Duckworth, A.L. (2014). The grit effect: predicting retention in the military, the workplace, school, and marriage. Journal of Personality Science and Individual Differences, Vol. 5, Article 36, page 1-12. DOI. 10.3389/fpsyg.2014.00036

Leung, S. A., Hou, Z. J., Gati, I., \& Li, X. (2011). Effects of parental expectations and cultural-values orientation on career decisionmaking difficulties of Chinese University students. Journal of Vocational Behavior, 78(1), 1120.

http://doi.org/10.1016/i.jvb.2010.0 8.004.

Li, X., Hou, Z.-J., \& Jia, Y. (2015). The influence of social comparison on career decision-making: Vocational identity as a moderator and regret as a mediator. Journal of Vocational Behavior, 86, 1019.

http://doi.org/10.1016/j.jvb.2014.1 0.003

Neugebauer, R., Hippmann, S., Leis, M., \& Landherr, M. (2016). Industrie 4.0-From the Perspective of Applied Research. Procedia CIRP, Vol. 57, pp. 2-7.

Prasetyo, Hoedi., \& Wahyudi, Sutopo. (2017). Industri 4.0: Telaah Klasifikasi Aspek dan Arah Perkembangan Riset. Jurnal Teknik Industri UNDIP, Vol. 13, No. 1, Januari 2018.

Rüßmann, M., Lorenz, M., Gerbert, P., Waldner, M., Justus, J., Engel, P. \& Harnisch, M. (2015). Industry 4.0: The future of productivity and growth in manufacturing industries. Boston Consulting Group, p.14. 